\title{
Diagnóstico Participativo de Riscos (DeParis) aplicado ao ambiente de trabalho dos docentes de uma instituição federal de ensino superior
}

Rodolfo Benedito da Silva Universidade Federal do Rio Grande do Sul (UFRGS), Porto Alegre, Rio Grande do Sul, Brasil

Fernando Gonçalves Amaral amaral@producao.ufrgs.br

Universidade Federal do Rio Grande do Sul (UFRGS), Porto Alegre, Rio Grande do Sul, Brasil

\author{
RESUMO
}

O ambiente de trabalho dos docentes em instituições públicas de ensino superior é caracterizado por diversos fatores de riscos que podem provocar danos à saúde e integridade física destes profissionais. Estes fatores têm origem, na grande maioria dos casos, na execução das atividades em instalações físicas inadequadas, seja pelo funcionamento em espaços provisórios, ou até mesmo pela ausência de manutenções periódicas nos prédios e equipamentos. Sendo assim, o presente trabalho teve como objetivo fazer uso do método DeParis para identificar, analisar e propor ações para eliminação e/ou minimização dos riscos existentes no ambiente de trabalho dos docentes de uma instituição federal de ensino superior. Para isto, alguns profissionais foram envolvidos de forma participativa no processo, auxiliando na análise do ambiente de trabalho e na identificação dos riscos. Com os resultados obtidos constatou-se que a metodologia utilizada se mostrou eficaz na identificação e análise de condições satisfatórias, das que precisam ser melhoradas e insatisfatórias, bem como na proposição de ações com responsáveis e prazos para suas conclusões, visando proporcionar um ambiente de trabalho com melhores condições para os docentes realizarem suas atividades.
\end{abstract}

PALAVRAS-CHAVE: DeParis. Ambiente de trabalho. Identificação de riscos. 


\section{INTRODUÇÃO}

As instituições de ensino superior desempenham um papel muito importante para o desenvolvimento de uma nação. Isto, por que, segundo Touriñám (2004), a presença do ensino superior em uma determinada região, representa um investimento para o futuro, proporcionando a formação de capital intelectual altamente qualificado, além de constituir uma fonte de conhecimento, consultoria e pesquisa que podem ser utilizadas pelas organizações e indústrias.

De acordo com Mazzilli (2011), no processo de implantação do sistema de ensino superior no país, foram incorporados modelos que envolvem as denominadas funções clássicas da universidade, sendo elas: de manutenção e transmissão da cultura, de ensino das profissões e de aumento e renovação do conhecimento.

As principais funções da universidade estão baseadas em três dimensões, que é o ensino, a pesquisa e a extensão. No âmbito do ensino, consubstanciado na forma de apropriação, pelos estudantes, do conhecimento que historicamente foi produzido pela humanidade. Já a pesquisa remete à geração de novos conhecimentos partindo de problemas emergentes da prática social. Por fim, a extensão direciona para a interferência nos processos sociais, bem como na identificação de problemas práticos que podem demandar novas pesquisas para solucioná-los (MAZZILLI, 2011).

Diante do reconhecimento do papel da universidade como um mecanismo para transformação social, desenvolvimento sustentável e inclusão do Brasil, de maneira competitiva, no cenário internacional, cresceram as mobilizações dos movimentos reivindicatórios de expansão da educação superior pública e gratuita (MEC, 2012).

No ano de 2001, com o intuito de dar cumprimento ao disposto na Constituição, foi criado o Plano Nacional de Educação - PNE (2001-2010), onde foram fixadas metas que requeriam um aumento considerável dos investimentos nessa área, além de metas que visavam a ampliação do número de estudantes atendidos em todos os níveis da educação superior (MEC, 2012).

Neste sentido, foram estabelecidos entre os anos de 2003 e 2012 os programas de expansão do ensino superior federal, em que a primeira fase, chamada de Expansão I, compreendeu o período de 2003 e 2007 com o objetivo de interiorizar o ensino público federal que possuía até o ano de 2002, quarenta e cinco universidades federais e cento e quarenta e oito campus/unidades. Em 24 de abril de 2007, foi instituído através do Decreto no 6.096, o Programa de Apoio a Planos de Reestruturação e Expansão das Universidades Federais (REUNI), que tinha como objetivo principal expandir o acesso e a permanência na educação superior, em nível de graduação, bem como melhorar o aproveitamento das estruturas físicas e dos recursos humanos das universidades federais (MEC, 2012). A implementação do REUNI foi originalmente prevista para o período de 2008 a 2012.

Para suportar esta crescente ampliação da oferta de vagas nas universidades federais, foram planejadas construções e readequações de instalações físicas, tais como: salas de aulas, bibliotecas, espaços de convivência, laboratórios, 
restaurantes universitários, salas de docentes, salas administrativas, moradias estudantis, dentre outras.

Entretanto, as fases de planejamento e execução destas obras não acompanharam a evolução da ampliação do número de vagas, resultando em atrasos. Tais atrasados, foram motivados principalmente por entraves licitatórios, cancelamento de contratos, atrasos nas emissões de licenças ambientais e até mesmo pelo aquecimento do mercado da construção civil, tendo em vista os investimentos dos setores públicos e privados através do Programa de Aceleração do Crescimento (PAC). O fato das instalações físicas não estarem prontas a tempo de acolher os estudantes dos novos cursos, provocaram transtornos operacionais, administrativos e pedagógicos (MEC, 2012).

No âmbito dos transtornos operacionais, está o funcionamento dos cursos em instalações físicas provisórias, inacabadas e até mesmo com problemas estruturais. Estas situações, têm contribuído para o surgimento de fatores de riscos nos ambientes de trabalhos dos técnicos administrativos e docentes (sujeitos do estudo em questão), podendo provocar danos à saúde e integridade física.

Além destes fatores, o ritmo de trabalho acelerado, esforço físico e ambiente de trabalho estressante contribuem para o agravamento dos danos à saúde dos docentes, levando-os a quadros de estresse, lombalgia (decorrentes de esforços posturais), faringite (uso excessivo da voz), dentre outros (LIMA e LIMAFILHO, 2009).

Nesta mesma linha de pensamento, outros autores como Porto, Almeida e Teixeira (2013) afirmam que os docentes estão frequentemente expostos à esforços repetitivos. Estes autores ressaltam ainda que, devido ao fato destes profissionais representarem um grupo numericamente expressivo da população, faz-se necessário realizar a investigação das ocorrências das doenças decorrentes do trabalho que, geralmente, são provocadas devido à realização de atividades não planejadas, ou até mesmo sem levar em conta as condições ambientais favoráveis e apropriadas para os profissionais.

Diante do exposto, surge a seguinte questão de pesquisa: como o método DeParis pode auxiliar na identificação e na sugestão de melhorias para eliminação e/ou redução dos riscos encontrados no ambiente de trabalho dos docentes de uma instituição federal de ensino superior?

Sendo assim, a hipótese que norteou o presente estudo parte da premissa de que, o funcionamento em espaço provisório do campus de uma universidade federal localizada na região centro-oeste brasileira, tem afetado o desenvolvimento das atividades dos docentes e se caracteriza como um ambiente propício para provocar danos à saúde e integridade física destes profissionais.

Deste modo, o estudo teve como objetivo fazer uso do método DeParis para identificação e análise de riscos no ambiente de trabalho analisado, bem como propor soluções para eliminar ou mitigar os impactos destes fatores de riscos. Para isto, os docentes foram envolvidos de forma participativa neste processo.

$\mathrm{O}$ artigo está estruturado em cinco seções, incluindo esta introdução. Na seção 2, é apresentada a revisão bibliográfica acerca dos temas abordados. Já na seção 3, são apresentados os procedimentos metodológicos utilizados no estudo. 
Em seguida, na seção 4, são apresentados os resultados obtidos. Por fim, a seção 5 traz as considerações finais, destacando os resultados relevantes e as sugestões para trabalhos futuros.

\section{REVISÃO BIBLIOGRÁFICA}

\section{ANÁLISE DE RISCOS EM AMBIENTES DE TRABALHO}

O risco pode ser definido como um termo utilizado para descrever o contexto de uma circunstância de perigo, ou seja, a concretização de um evento indesejado (SÁNCHEZ, 2013).

Diante deste contexto, os mecanismos de gestão de riscos ambientais têm se configurado como instrumentos cada vez mais fundamentais para caracterizar, minimizar e/ou até mesmo eliminar os potenciais riscos nos ambientes de trabalho das organizações (BISSACOT e OLIVEIRA, 2016).

Neste sentido, o processo de identificação e reconhecimento dos riscos presentes nos ambientes de trabalho, consiste na primeira etapa da higiene ocupacional. Por sua vez, a higiene ocupacional é definida como:

\footnotetext{
a ciência que atua no campo da saúde ocupacional, por meio da antecipação, do reconhecimento, da avaliação e do controle dos riscos físicos, químicos e biológicos originados nos locais de trabalho e passíveis de produzir danos à saúde dos trabalhadores, observando-se seu impacto no meio ambiente (SALIBA, 2010, p. 22).
}

De acordo com Brevigliero, Possebon e Spinelli (2010), deve-se dar atenção especial a esta etapa de identificação e reconhecimento, visto que se algum fator de risco não for identificado, muito provavelmente ele não será analisado e nem monitorado.

Já Saliba (2011) ressalta que no processo de reconhecimento de riscos, são necessários conhecimentos profundos dos produtos envolvidos no processo produtivo, métodos de trabalho utilizados, fluxo dos produtos e processos, layout das instalações, bem como da quantidade de trabalhadores envolvidos em cada etapa do processo.

Existem na literatura diversos métodos para mensuração dos riscos ocupacionais. De forma proporcional, pouca atenção é dada para definir ações práticas que podem ser realizadas para minimizar a exposição dos trabalhadores. A grande maioria desses métodos realiza a análise das situações de trabalhos de forma quantitativa e, posteriormente, são tomadas medidas que minimizem os riscos existentes.

Entretanto, na grande maioria das situações analisadas, medidas prevencionistas podem ser adotadas de modo imediato com base na observação simples realizada por profissionais que estão preocupados diretamente com estas situações e que possuem conhecimento detalhado das mesmas, visto que estão envolvidos com elas no seu dia-a-dia (MALCHAIRE, 2004). 
O Diagnóstico Participativo de Riscos (DeParis) consiste em um método que tem como ênfase a abordagem qualitativa de análise de riscos para todas as situações de trabalho existentes no cotidiano da empresa. Além disso, ele requer a elaboração de um plano de ação com o intuito de implantar as melhorias propostas para todos os trabalhadores e processos, bem como desenvolver a cultura da ergonomia relacionada à segurança no trabalho (MALCHAIRE, 2003).

\section{O MÉTODO DE DIAGNÓSTICO PARTICIPATIVO DE RISCO - DEPARIS}

De acordo com Malchaire (2003), o método DeParis faz parte da estratégia SOBANE (Screening, Observation, Analysis, Expertise) de gestão de riscos e se baseia na prevenção de riscos por meio de um método estruturado, que pode ser aplicado a qualquer organização. Ele tem como objetivo realizar uma abordagem progressiva nas situações de trabalho em pequenas e grandes empresas, coordenar a colaboração entre os colaboradores que atuam nos diversos níveis da organização, visando realizar uma prevenção mais rápida, eficaz e com um menor custo.

A estratégia SOBANE descreve quatro níveis, conforme apresentado a seguir:

1) Diagnóstico preliminar: neste nível, os fatores de risco são identificados e as soluções evidentes são colocadas em prática;

2) Observação: no segundo nível, são aprofundadas as discussões em relação aos fatores de risco que não puderam ser solucionados no primeiro nível, discutindo-se as causas e soluções de forma mais detalhada;

3) Análise: neste nível, recorre-se (se necessário) a um prevencionista para quantificar medições indispensáveis para o desenvolvimento de soluções específicas;

4) Perícia: em situações raras em que a presença de um especialista se torna imprescindível para analisar e resolver um problema específico.

Deste modo, a cada nível, buscam-se as soluções de melhoria das situações de trabalho. Somente recorre-se ao recurso do nível seguinte, caso as melhorias propostas não forem suficientes para solucionar os problemas encontrados e as condições de trabalho continuam inaceitáveis (MALCHAIRE, 2003).

A Figura 1 apresenta um esquema geral da estratégia SOBANE de gerenciamento dos riscos.

Figura 1 - Estratégia SOBANE de gerenciamento de riscos

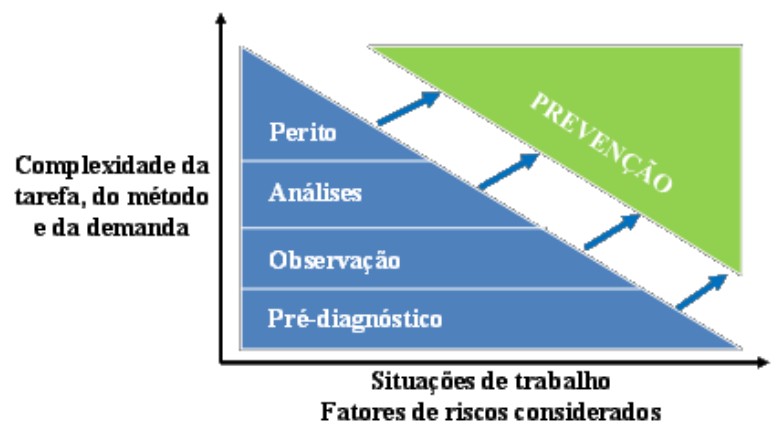

Fonte: Malchaire (2003, p. 21) 
O método DeParis está estruturado sob a forma de 18 rubricas, que questionam as condições de trabalho em relação aos seguintes itens: 1) zonas de trabalho; 2) organização técnica entre postos; 3) locais de trabalho; 4) riscos de acidentes; 5) comandos e sinais; 6) ferramentas e material de trabalho; 7) trabalho repetitivo; 8) manuseios/levantamento de peso; 9) carga mental; 10) iluminação; 11) ruído; 12) ambientes térmicos; 13) riscos químicos e biológicos; 14) vibrações; 15$)$ relações de trabalho entre trabalhadores; 16$)$ ambiente social local e geral; 17) conteúdo do trabalho; 18) ambiente psicossocial.

O questionário sugere que, em cada rubrica, o participante realize uma descrição breve da situação desejada e uma lista dos itens a serem posteriormente monitorados. Por fim, deve-se fazer um julgamento global do item analisado por meio de um sistema figurativo de cores e expressões faciais.

Deste modo, a expressão facial acompanhada da cor verde indica uma situação satisfatória. Já a expressão facial com a cor amarela sinaliza para uma situação mediana que pode ser melhorada, se possível. Por fim, a expressão facial com a cor vermelha representa uma situação insatisfatória, passível de ser perigosa, que deve ser melhorada.

A Figura 2 ilustra a forma como cada rubrica é apresentada no processo de diagnóstico de riscos.

Figura 2 - Forma de apresentação de cada rubrica

\begin{tabular}{|l|l|}
\hline RUBRICA \\
\hline Situação desejada: & $\begin{array}{l}\text { O que fazer de concreto } \\
\text { para melhorar a } \\
\text { situação? }\end{array}$ \\
\hline A controlar: & \\
\hline $\begin{array}{l}\text { Aspectos a serem estudados com mais } \\
\text { detalhes: }\end{array}$ & $\Theta$ \\
\hline
\end{tabular}

Fonte: Malchaire (2003)

\section{PROCEDIMENTOS METODOLÓGICOS}

Segundo Prodanov e Freitas (2013), uma pesquisa científica pode ser classificada em quatro categorias que se dividem quanto: i) à natureza da pesquisa; ii) à abordagem do problema; iii) aos objetivos; e, iv) aos procedimentos utilizados.

Diante deste contexto, esta pesquisa é classificada conforme exposto na Tabela 1.

Tabela 1 - Classificação da pesquisa

$\begin{array}{cc}\text { Categorias } & \text { Classificação } \\ \text { Natureza } & \text { Pesquisa aplicada } \\ \text { Abordagem } & \text { Pesquisa qualitativa } \\ \text { Objetivos } & \text { Pesquisa exploratória } \\ \text { Procedimentos } & \text { Estudo de caso }\end{array}$


Na pesquisa aplicada, o principal objetivo é a geração de conhecimentos para aplicação prática voltados à resolução de problemas específicos, envolvendo verdades e interesses locais (PRODANOV e FREITAS, 2013). Esta classificação, se deve ao fato que no presente trabalho, buscou-se avaliar os riscos ambientais existentes no ambiente de trabalho dos docentes de uma instituição federal de ensino superior, bem como propor melhorias para a minimização ou eliminação dos mesmos.

Já a pesquisa qualitativa, é aquela que não se preocupa em traduzir informações e dados numericamente, tendo como objetivo a análise da relação entre a realidade e o objeto estudado, de modo a obter diversas interpretações de um julgamento indutivo por parte do observador (RAMOS; RAMOS e BUSNELLO, 2005). Tal classificação se deve ao fato que neste estudo, fez-se o uso de um método qualitativo no processo de identificação e análise de riscos ambientais, que é o método DeParis.

A pesquisa exploratória busca proporcionar maiores informações sobre o assunto em estudo, facilitar a delimitação do tema trabalhado, definir os objetivos ou formular as hipóteses da pesquisa, ou ainda, descobrir um novo enfoque para o trabalho que se deseja desenvolver. Este tipo de pesquisa assume as formas de pesquisas bibliográficas e estudos de caso (GIL, 2008).

Por fim, o estudo de caso, apresenta como característica o estudo aprofundado de um ou de poucos objetos, de modo a permitir o seu conhecimento amplo e detalhado (GIL, 2008).

Deste modo, para atingir o objetivo proposto, o trabalho foi conduzido em duas etapas, conforme apresentado a seguir:

1a Etapa - análise do ambiente de trabalho: nesta etapa foi feito um levantamento das instalações físicas do local analisado por meio de medições do espaço físico, equipamentos e mobiliários utilizados pelos docentes na execução de suas atividades. Além disso, foram feitos levantamentos das informações do número de docentes que ocupam o espaço atualmente e registros fotográficos, tanto para análise das demandas espaciais e de infraestrutura, quanto para identificação de fatores de riscos;

2a Etapa - levantamento de riscos: para fazer o levantamento de riscos no ambiente de trabalho foi aplicado um questionário por meio do método de Diagnóstico Participativo de Risco - DeParis (MALCHAIRE, 2003), que faz parte da estratégia SOBANE (Screening, Observation, Analysis, Expertise), apresentada pelo mesmo autor.

Cabe ressaltar, que o método DeParis permite a adaptação da ferramenta de acordo com a situação analisada, podendo modificar os termos, eliminar aspectos que não são aplicáveis, modificando alguns ou até mesmo incluindo outros aspectos complementares.

Neste sentido, no presente trabalho foram abordadas apenas as rubricas 1 , $3,4,6,10,11,12,15,16$ e 18, respectivamente, referentes à: zonas de trabalho; locais de trabalho; riscos de acidentes; ferramentas e materiais de trabalho; iluminação; ruído; ambientes térmicos; relações de trabalho entre trabalhadores; ambiente social local e geral; ambiente psicossocial. 
O questionário com estas dez rubricas foi aplicado por um período de aproximadamente duas horas com a participação de quatro docentes. Esta quantidade de pessoas envolvidas na aplicação do questionário, segue a orientação do método DeParis, que recomenda que o processo de levantamento de riscos envolva de três a sete participantes.

Sendo assim, os docentes estavam no centro da prevenção, contribuindo não apenas para apresentarem suas opiniões ou responderem questões, mas também para promoverem a discussão dos detalhes práticos que permita a execução do trabalho em condições desejáveis para eles e para a instituição.

\section{APRESENTAÇÃO E DISCUSSÃO DOS RESULTADOS}

\section{A INSTITUIÇÃO}

A instituição federal de ensino superior analisada no presente trabalho, foi instituída sob a forma de fundação, em 10 de dezembro de 1970, sendo que atualmente possui seis campus, dos quais, dois estão localizados na capital e os demais no interior do estado. O campus I da capital é o maior deles e é onde está localizada, além das unidades acadêmicas, toda a estrutura administrativa da instituição (reitoria e pró-reitorias). Já o campus II, está atualmente em construção.

O campus a que este estudo se refere, é um dos que estão localizados no interior, na região metropolitana da capital. A implantação deste campus, assim como do campus II da capital, é fruto da adesão da instituição ao programa de Reestruturação Universitária (REUNI) no ano de 2008.

O projeto de implantação do campus em questão começou a ser concebido em 2012, iniciando suas atividades no ano de 2014 com cinco cursos de graduação, sendo eles: Engenharia de Transportes, Engenharia de Minas, Engenharia Química, Engenharia de Computação e Engenharia de Controle e Automação.

Entretanto, como citado anteriormente, o ritmo das obras não acompanhou a evolução da ampliação do número de vagas. O campus está atualmente em construção e desde 2014 funciona em um espaço provisório do campus I da capital, carecendo de ambiente de trabalho propício para os servidores técnicos e docentes executarem de modo adequado as suas atividades, além de oferecer riscos à saúde e integridade física dos mesmos.

O quadro de servidores do campus é composto por 70 profissionais, distribuídos conforme apresentado no Quadro 1.

Quadro 1 - Quantidade e distribuição dos servidores do campus

\begin{tabular}{|c|c|}
\hline Servidores & Quantidade \\
\hline Docentes & 50 \\
\hline Técnicos administrativos & 20 \\
\hline Total & 70 \\
\hline
\end{tabular}

Destes 50 docentes, 33 são do sexo feminino e 17 do sexo masculino, sendo que 21 possuem o título de doutor e 29 de mestre. 


\section{RESULTADOS DO QUESTIONÁRIO DEPARIS}

O ambiente de trabalho avaliado no presente estudo, é uma sala de professores, onde os docentes realizam as atividades de atendimento a alunos, preparo de aulas, atividades de pesquisa e extensão, compreendendo uma área de $177,38 \mathrm{~m}^{2}$.

As informações obtidas por meio da aplicação prática do método de Diagnóstico Participativo de Risco (DeParis) com os quatros docentes, quanto ao ambiente de trabalho analisado são apresentados no Quadro 2.

Quadro 2: Informações do ambiente de trabalho obtidas com aplicação do DeParis

\begin{tabular}{|c|c|c|c|c|c|c|}
\hline \multirow[b]{2}{*}{ № } & \multirow[b]{2}{*}{ Rubrica } & \multirow[b]{2}{*}{ Respostas } & \multicolumn{3}{|c|}{ Condição } & \multirow[b]{2}{*}{ Ações } \\
\hline & & & 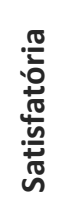 & 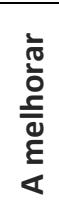 & 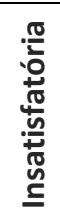 & \\
\hline \multirow{5}{*}{1} & \multirow{5}{*}{$\begin{array}{c}\text { As zonas de } \\
\text { trabalho }\end{array}$} & $\begin{array}{l}\text { A mesa de trabalho é muito } \\
\text { pequena, sendo que todo o } \\
\text { espaço disponível para } \\
\text { trabalho é ocupado pelo } \\
\text { computador (gabinete, } \\
\text { monitor, teclado e mouse), } \\
\text { não tendo espaço suficiente } \\
\text { para o docente realizar de } \\
\text { modo confortável outras } \\
\text { atividades, tais como } \\
\text { correções de provas e } \\
\text { trabalhos, preparo de aulas, } \\
\text { dentre outras. }\end{array}$ & & & (2) & $\begin{array}{c}\text { Adquirir } \\
\text { novas mesas } \\
\text { e promover } \\
\text { mudança no } \\
\text { layout. }\end{array}$ \\
\hline & & $\begin{array}{c}\text { As vias possuem largura maior } \\
\text { que } 80 \mathrm{~cm} \text {. Entretanto, com o } \\
\text { layout atual, há obstruções } \\
\text { com cadeiras para ter acesso } \\
\text { na grande maioria das mesas } \\
\text { de trabalho. }\end{array}$ & & & & $\begin{array}{l}\text { Promover } \\
\text { mudança no } \\
\text { layout. }\end{array}$ \\
\hline & & $\begin{array}{l}\text { As únicas duas janelas } \\
\text { existentes no ambiente estão } \\
\text { tampadas com papéis. }\end{array}$ & & ;) & & $\begin{array}{l}\text { Fazer } \\
\text { aquisição e } \\
\text { instalação } \\
\text { de cortinas } \\
\text { persianas. }\end{array}$ \\
\hline & & $\begin{array}{l}\text { Os pisos são nivelados e não } \\
\text { escorregadios. Além disso, } \\
\text { permanecem sempre limpos } \\
\text { pelo fato que há uma } \\
\text { colaboradora terceirizada que } \\
\text { realiza a limpeza do local duas } \\
\text { vezes por dia. }\end{array}$ & (i) & & & - \\
\hline & & $\begin{array}{l}\text { Há pontos nas paredes que } \\
\text { foram realizados reparos na } \\
\text { parte estrutural e não foram } \\
\text { realizadas as pinturas } \\
\text { novamente. }\end{array}$ & & :) & & $\begin{array}{l}\text { Realizar a } \\
\text { pintura das } \\
\text { paredes. }\end{array}$ \\
\hline
\end{tabular}




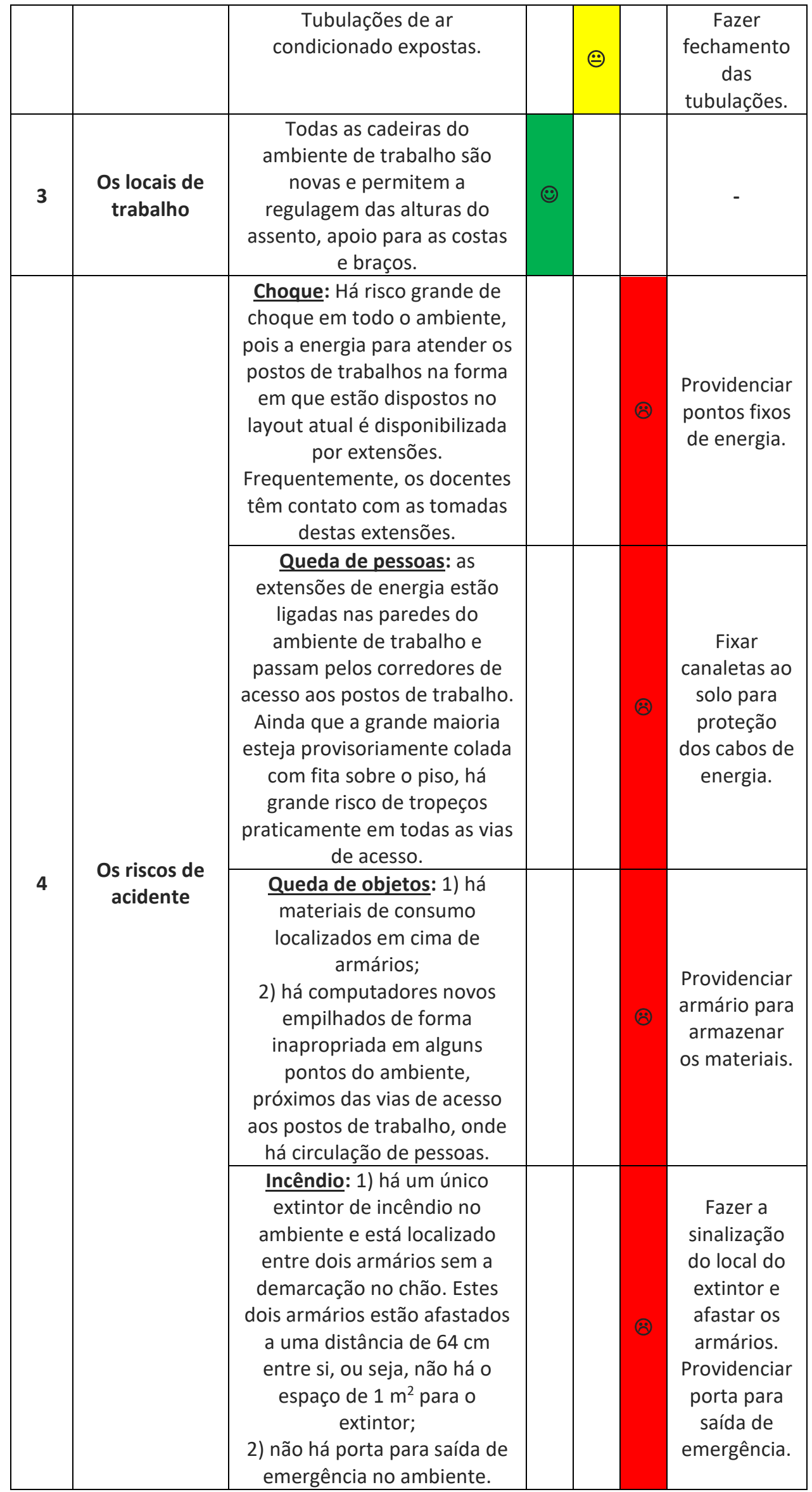




\begin{tabular}{|c|c|c|c|c|c|}
\hline & & $\begin{array}{l}\text { Existe uma única porta de } 80 \\
\mathrm{~cm} \text { para entrada e saída do } \\
\text { local. Esta porta possibilita o } \\
\text { acesso a um corredor e não } \\
\text { permite acesso direto a uma } \\
\text { área externa. } \\
\end{array}$ & & & \\
\hline & & $\begin{array}{l}\text { Os computadores e } \\
\text { impressora são novos. }\end{array}$ & (:) & & - \\
\hline 6 & $\begin{array}{l}\text { As } \\
\text { ferramentas e } \\
\text { materiais de } \\
\text { trabalho }\end{array}$ & $\begin{array}{l}\text { Algumas vezes há dificuldades } \\
\text { para fazer impressões devido } \\
\text { a conexão do computador } \\
\text { com a impressora. Além disso, } \\
\text { em alguns momentos a } \\
\text { impressão de documentos } \\
\text { não apresenta boa qualidade } \\
\text { devido à tinta de impressão. }\end{array}$ & & $\oplus$ & $\begin{array}{l}\text { Fazer } \\
\text { revisões } \\
\text { periódicas } \\
\text { nos } \\
\text { cartuchos de } \\
\text { tintas. }\end{array}$ \\
\hline 10 & A iluminação & $\begin{array}{l}\text { A luminosidade é baixa nas } \\
\text { penúltima e última fileiras de } \\
\text { mesas, localizadas ao lado } \\
\text { direito quando se entra no } \\
\text { ambiente. }\end{array}$ & & $\oplus$ & $\begin{array}{l}\text { Providenciar } \\
\text { a instalação } \\
\text { de } \\
\text { lâmpadas. }\end{array}$ \\
\hline 11 & O ruído & $\begin{array}{l}\text { A principal fonte de ruído é } \\
\text { proveniente de conversas } \\
\text { entre os docentes e durante o } \\
\text { atendimento de alunos, } \\
\text { causando distração e } \\
\text { desconforto, principalmente } \\
\text { quando há um número } \\
\text { elevado de pessoas no local. }\end{array}$ & & $\oplus$ & $\begin{array}{l}\text { Disponibiliza } \\
\quad \text { r um } \\
\text { ambiente } \\
\quad \text { para } \\
\text { atendimento } \\
\text { s aos alunos. }\end{array}$ \\
\hline 12 & $\begin{array}{l}\text { Os ambientes } \\
\text { térmicos }\end{array}$ & $\begin{array}{l}\text { O ambiente é quente nos dias } \\
\text { em que as temperaturas estão } \\
\text { elevadas. Está faltando um ar } \\
\text { condicionado no local, } \\
\text { contribuindo para o } \\
\text { desconforto no ambiente em } \\
\text { dias de muito calor. }\end{array}$ & & $\oplus$ & $\begin{array}{c}\text { Solicitar a } \\
\text { colocação e } \\
\text { manutençõe } \\
\text { s periódicas } \\
\text { dos } \\
\text { aparelhos de } \\
\text { ar } \\
\text { condicionad } \\
\text { o. } \\
\end{array}$ \\
\hline \multirow[t]{2}{*}{15} & \multirow{2}{*}{$\begin{array}{l}\text { As relações de } \\
\text { trabalho } \\
\text { entre } \\
\text { trabalhadores }\end{array}$} & $\begin{array}{l}\text { Cada docente tem autonomia } \\
\text { na gestão de suas tarefas, de } \\
\text { modo que cumpram a carga } \\
\text { horária de } 40 \text { horas semanais } \\
\text { entre atividades de ensino, } \\
\text { pesquisa e extensão. }\end{array}$ & (:) & & - \\
\hline & & $\begin{array}{c}\text { As relações hierárquicas são } \\
\text { harmoniosas e não há } \\
\text { conflitos entre os pares } \\
\text { (docentes). }\end{array}$ & (:) & & - \\
\hline 16 & $\begin{array}{c}\text { O ambiente } \\
\text { social local e } \\
\text { geral }\end{array}$ & $\begin{array}{l}\text { O local social onde fica } \\
\text { disponível água, café e } \\
\text { refeições que estão } \\
\text { disponíveis aos docentes, } \\
\text { assim como os sanitários são } \\
\text { limpos e organizados. }\end{array}$ & (:) & & - \\
\hline 18 & O ambiente & Há um bom clima social entre & (:) & & - \\
\hline
\end{tabular}




\begin{tabular}{|c|c|c|c|c|c|}
\hline psicossocial & $\begin{array}{c}\text { docentes e destes com os } \\
\text { dirigentes da instituição. }\end{array}$ & & & \\
\hline & $\begin{array}{c}\text { A instituição oferece suporte } \\
\text { para acompanhamento } \\
\text { psicológico dos docentes. }\end{array}$ & (-) & & & - \\
\hline $\begin{array}{c}\text { Há insatisfação por parte da } \\
\text { grande maioria dos docentes } \\
\text { com relação ao ambiente de } \\
\text { trabalho que é objeto de } \\
\text { estudo. Há exigência } \\
\text { expressiva para adequações } \\
\text { do local. }\end{array}$ & (2) & $\begin{array}{c}\text { Promer } \\
\text { mudança no } \\
\text { layout. }\end{array}$ \\
\hline
\end{tabular}

Pode-se verificar no Quadro 2, que o ambiente de trabalho possui algumas condições satisfatórias, tais como: pisos nivelados, não escorregadios e limpos; cadeiras novas e que possibilitam a regulagem das alturas do assento, apoio para as costas e braços; equipamentos como computadores e impressoras novos; os docentes possuem autonomia na gestão das suas atividades; os ambientes para convívio social são limpos e organizados; existência de bom relacionamento entre os docentes e os gestores (pró-reitor e diretor); e, por fim, acompanhamento psicológico para os docentes em casos de necessidade.

Por outro lado, constata-se ainda no Quadro 2, que o ambiente de trabalho dos docentes possui condições que precisam ser melhoradas e também outras que se apresentam como insatisfatórias.

Dentre as que precisam ser melhoradas, destacam-se: janelas tampadas com papéis; algumas partes das paredes sem pintura; ferramenta de trabalho como a impressora que não apresentam bom funcionamento devido a problemas de conexão e tinta; ruído provocado por conversas entre os docentes e entre docentes e alunos; e, ambiente quente em dias de temperaturas elevadas, devido à ausência de um aparelho de ar condicionado.

Já as condições insatisfatórias são: mesas de trabalho pequenas; obstrução de acesso aos postos de trabalho por cadeiras; riscos de acidentes com choque devido ao contato com tomadas, quedas de pessoas e materiais, bem como de incêndio pela ausência de uma porta saída de emergência e extintor armazenado inadequadamente.

Os registros fotográficos das condições que precisam ser melhoradas, bem como das insatisfatórias (perigosas) relacionadas à primeira rubrica (zonas de trabalho), podem ser vistos através da Figura 4. 
Figura 4: Condições do ambiente relacionadas à primeira rubrica - zonas de trabalho

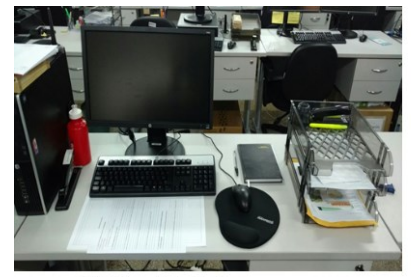

(a) Mesa de trabalho pequena

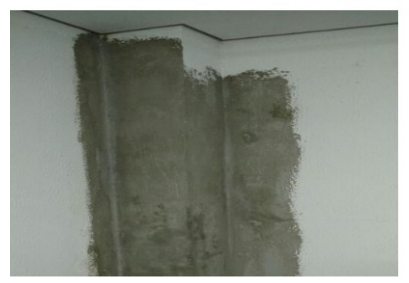

(c) Paredes sem pintura

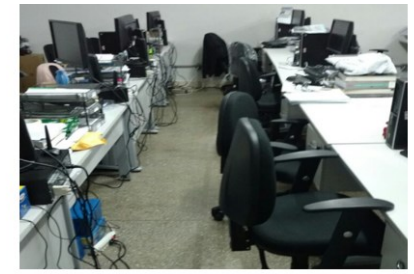

(b) Cadeiras que obstuem o acesso

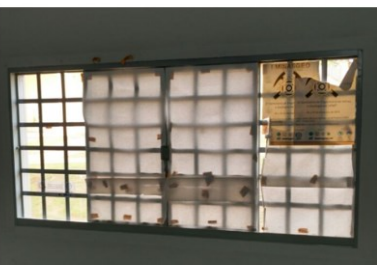

(d) Janelas tampadas com papéis

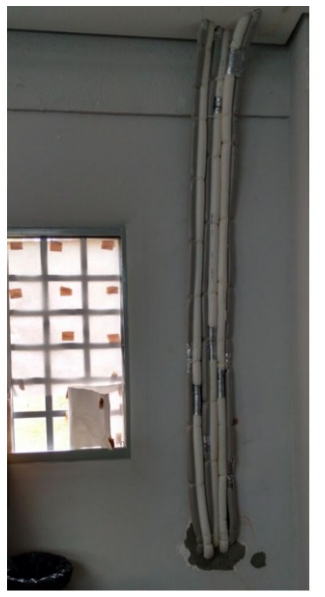

(e) Tubulaşōes de ar condicionado expostas

A Figura 5 também apresenta as condições que devem ser melhoradas e outras insatisfatórias (perigosas) relacionadas à quarta rubrica (riscos de acidente). Estas condições devem ser solucionadas com o intuito de tornar o ambiente de trabalho mais seguro.

Figura 5: Condições do ambiente relacionadas à quarta rubrica - riscos de acidente

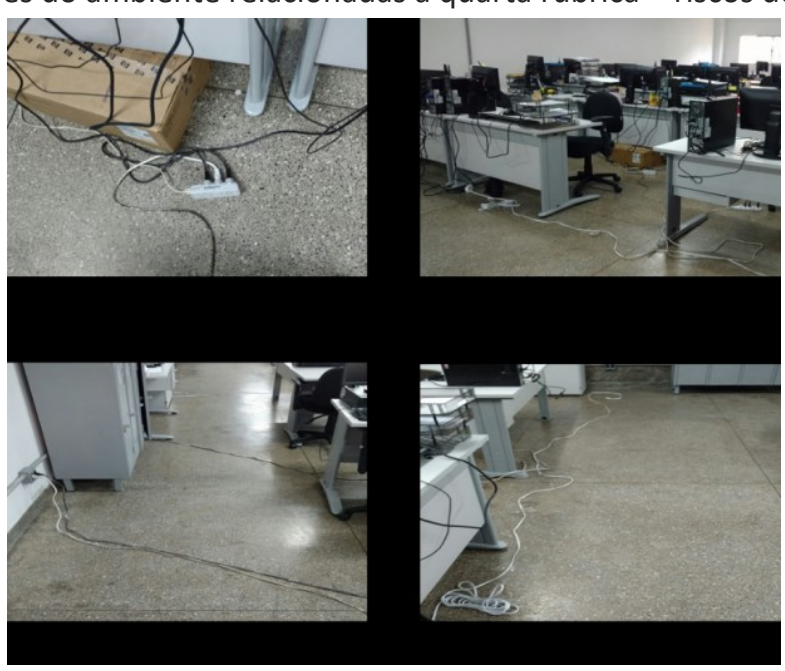

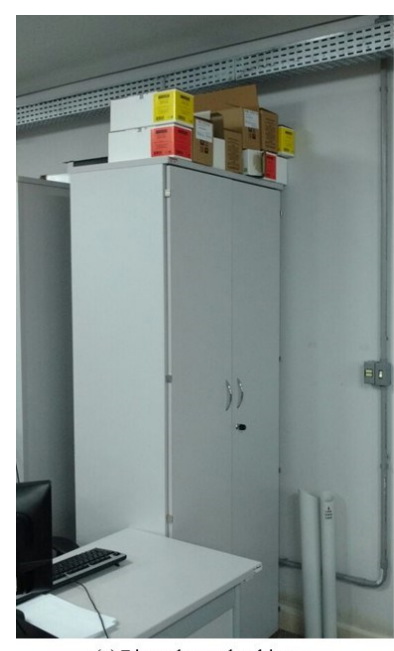

(e) Risco de queda objetos

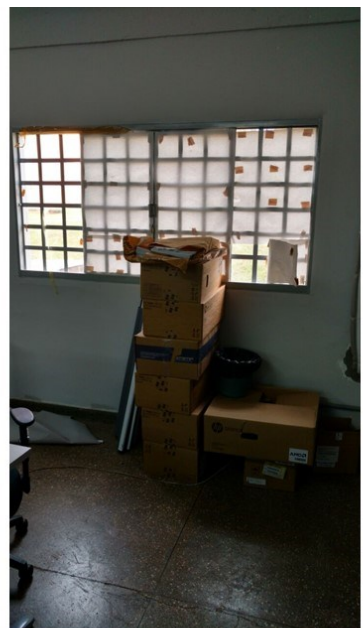

(f) Risco de queda objetos

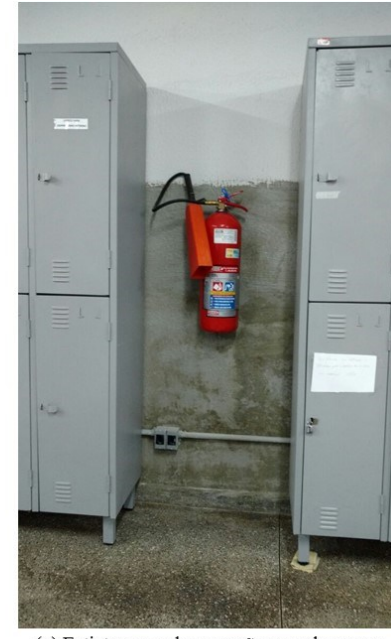

(g) Extintor sem demarcação no solo e com Espaço insuficiente 
Com o intuito de eliminar ou amenizar as condições que podem ser melhoradas e aquelas insatisfatórias consideradas como perigosas, foram propostas algumas ações para atingir este objetivo, conforme apresentado na última coluna do Quadro 2.

A seguir, no Quadro 3, são sintetizadas estas ações e apresentados os responsáveis pela execução de cada uma delas, bem como os respectivos prazos para suas conclusões.

Quadro 3: Síntese das ações de melhorias propostas com responsáveis e prazos

\begin{tabular}{|c|c|c|c|}
\hline № & Ações & Responsáveis & Prazos \\
\hline 1 & $\begin{array}{c}\text { Adquirir novas mesas e promover } \\
\text { mudança no layout }\end{array}$ & $\begin{array}{c}\text { Direção do } \\
\text { Campus/Docentes }\end{array}$ & 4 meses \\
\hline 2 & $\begin{array}{c}\text { Fazer aquisição e instalação de } \\
\text { cortinas persianas }\end{array}$ & Prefeitura do Campus & 1 mês \\
\hline 3 & Realizar a pintura das paredes & Prefeitura do Campus & 1 mês \\
\hline 4 & Fazer fechamento das tubulações & Prefeitura do Campus & 1 mês \\
\hline 5 & Providenciar pontos fixos de energia & Prefeitura do Campus & 2 meses \\
\hline 6 & $\begin{array}{c}\text { Fixar canaletas ao solo para proteção } \\
\text { dos cabos de energia }\end{array}$ & Prefeitura do Campus & 2 meses \\
\hline 7 & $\begin{array}{c}\text { Providenciar armário para armazenar } \\
\text { os materiais }\end{array}$ & Direção do Campus & 1 mês \\
\hline 8 & $\begin{array}{l}\text { Fazer a sinalização do local do } \\
\text { extintor e afastar os armários }\end{array}$ & Prefeitura do Campus & 1 mês \\
\hline 9 & $\begin{array}{c}\text { Providenciar porta para saída de } \\
\text { emergência }\end{array}$ & $\begin{array}{l}\text { Direção/Prefeitura do } \\
\text { Campus }\end{array}$ & 1 mês \\
\hline 10 & $\begin{array}{l}\text { Fazer revisões periódicas nos } \\
\text { cartuchos de tintas }\end{array}$ & $\begin{array}{l}\text { Técnico de informática e } \\
\text { redes }\end{array}$ & 1 mês \\
\hline 11 & $\begin{array}{c}\text { Providenciar a instalação de } \\
\text { lâmpadas }\end{array}$ & Prefeitura do Campus & 1 mês \\
\hline 12 & $\begin{array}{l}\text { Disponibilizar um ambiente para } \\
\text { atendimentos aos alunos }\end{array}$ & $\begin{array}{l}\text { Direção/Prefeitura do } \\
\text { Campus }\end{array}$ & 2 meses \\
\hline 13 & $\begin{array}{l}\text { Solicitar a colocação e manutenções } \\
\text { periódicas dos aparelhos de ar } \\
\text { condicionado }\end{array}$ & Prefeitura do Campus & 1 mês \\
\hline
\end{tabular}

De todas as ações propostas no Quadro 3, a primeira que é aquisição de mesas e mudança no layout do ambiente de trabalho, é a que requer um maior tempo para sua conclusão e um estudo mais detalhado para que possa proporcionar resultados satisfatórios.

Neste sentido, foi realizada uma análise do layout atual, levantamento do mobiliário e equipamentos existentes e, por fim, proposto um novo layout. Os móveis, equipamentos, quantidade e dimensões que estão atualmente dispostos no ambiente de trabalho são: 48 mesas de 1,20 x 0,60 metros; 1 mesa de 1,40 $\mathrm{x}$ 1,40 metros; 6 mesas de 1,60 x 1,60 metros; 6 armários de 1,23 x 0,43 metros; 3 mesas de 0,80 x 0,47 metros; 1 mesa de 0,80 × 0,48 metros; 1 impressora; 62 cadeiras; 46 computadores e 2 aparelhos de ar condicionado. A obtenção dessas informações foi necessária para que fosse possível ter o entendimento das características necessárias para a proposto do novo layout. 
O layout atual possui 12 fileiras de mesas não padronizadas, ou seja, possui mesas comuns e do tipo "L", além de não apresentar distâncias padronizadas entre as fileiras. O layout atual, além de não apresentar um bom aspecto visual do ambiente de trabalho, contribui para o surgimento de fatores, dentre os quais destacam-se: riscos de quedas devido à obstrução por cadeiras entre as fileiras e ao cruzamento de cabos de energia nas áreas de circulação; riscos de choques elétricos; e, insatisfação dos docentes pela falta de espaço nas mesas para realização das suas atividades.

A Figura 6 apresenta o layout atual do ambiente que tem a capacidade de alocar os docentes em 55 postos de trabalho. Já na Figura 7 é apresentado layout proposto.

A elaboração do novo layout foi realizada considerando o fato de estar em discussão por parte da direção da instituição, a destinação de um outro espaço para alocação de 12 docentes. Deste modo, no ambiente de trabalho analisado tem a necessidade de alocar 43 docentes, como pode ser visto na Figura 7.

Figura 6: Layout atual do ambiente de trabalho analisado

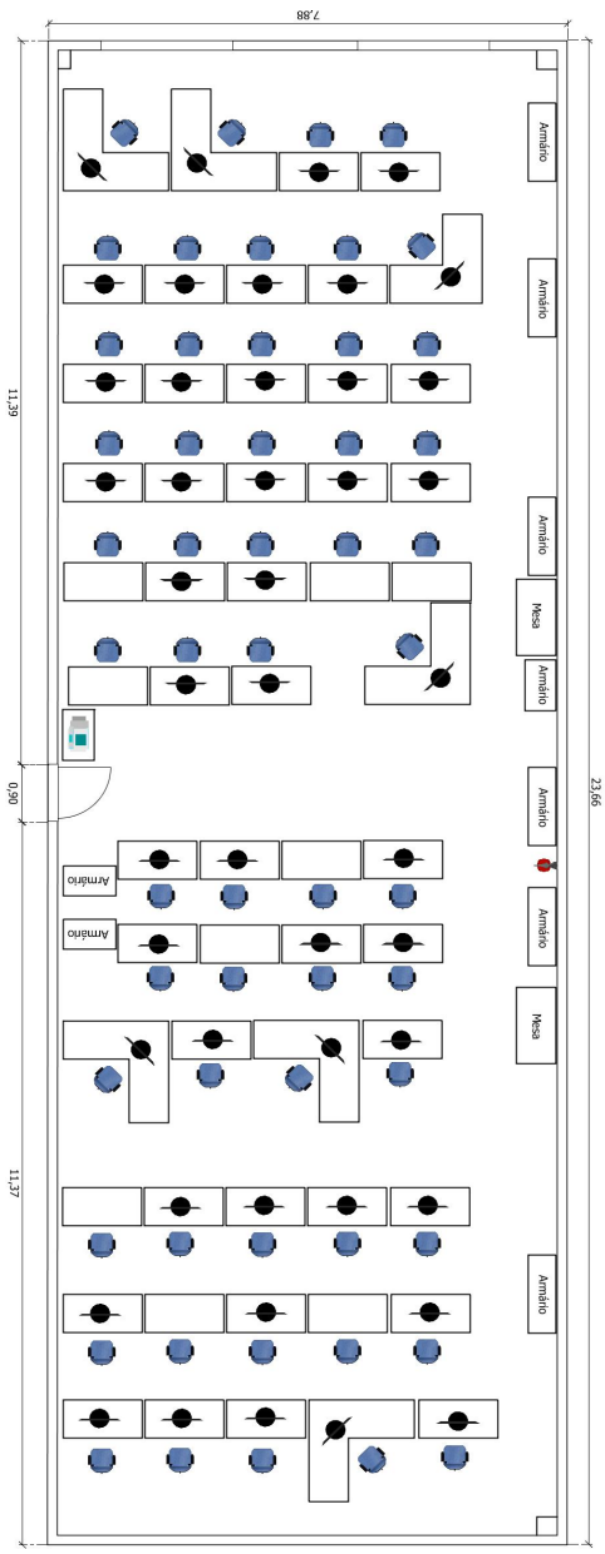


Figura 7: Layout proposto para o ambiente de trabalho

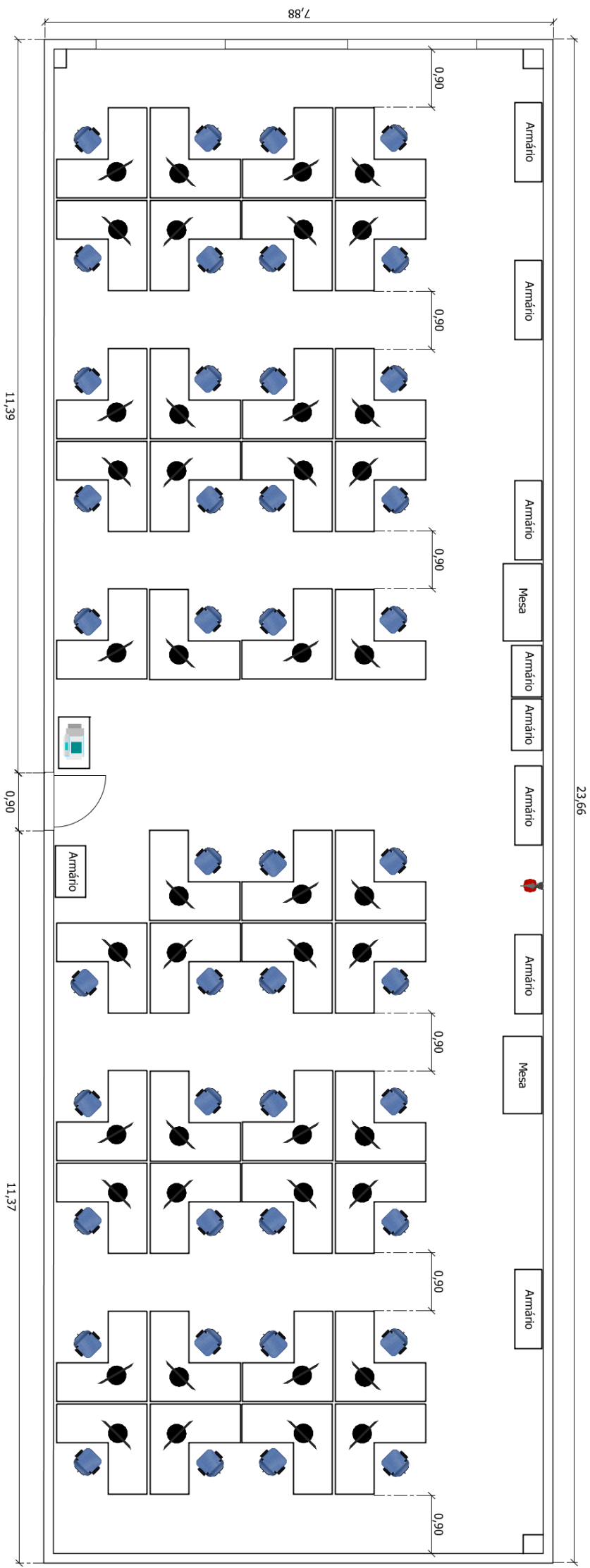


É possível observar ainda na Figura 7, que a implementação do novo layout aliado à execução das outras ações que foram propostas, proporcionará um melhor aspecto visual no ambiente de trabalho, permitindo assim a eliminação ou minimização dos outros fatores de riscos e aumentar a satisfação dos docentes que fazem uso deste espaço.

Isto, porque, o novo layout proporcionará um maior espaço entre as fileiras e entre as fileiras e paredes, sendo que foi considerada uma distância para circulação de pessoas de $90 \mathrm{~cm}$. Além disso, com esta nova disposição de mesas, as cadeiras não ficarão nos corredores, evitando o fluxo cruzado entre pessoas e mobiliário. Outro ponto considerado neste processo foi afastar os armários que estavam próximos ao extintor de incêndio, sendo possível destinar o espaço de 1 metro quadrado para a sinalização do local do extintor.

A aquisição de novas mesas do tipo " $\mathrm{L}$ " medindo $1,40 \times 1,40$ metros, proporcionará aos docentes um espaço de trabalho maior para desempenhar as suas atividades de modo adequado.

Sugere-se que este mobiliário seja adquirido seguindo as recomendações da Norma Regulamentadora 17 (NR-17), ou seja, "sem quinas vivas ou rebarbas, devendo os elementos de fixação (pregos, rebites, parafusos) ser mantidos de forma a não causar acidentes".

Sendo assim, para a implementação deste novo layout há necessidade de fazer a aquisição de 42 mesas com estas dimensões, visto que atualmente o ambiente de trabalho já possui uma mesa com estas características.

Cabe ressaltar, que as mesas comuns de 1,20 x 0,60 metros que tem no ambiente atualmente, poderão ser utilizadas nos laboratórios de informática no campus que está em construção.

Além disso, sugere-se que o novo espaço, que está sendo concebido para alocação dos outros 12 postos de trabalho, siga as orientações propostas na elaboração deste novo layout.

\section{CONCLUSÕES}

Este estudo tratou de uma problemática relacionada aos riscos presentes no ambiente de trabalho dos docentes de uma instituição federal de ensino superior. Tal problemática tem origem pelo funcionamento do campus em espaço provisório devido aos atrasos nas obras onde funcionará o campus permanentemente.

Esta situação tem afetado o desenvolvimento das atividades dos docentes, de modo que o local de trabalho se caracteriza como um ambiente propício para provocar danos à saúde e integridade física destes profissionais.

Deste modo, objetivou-se tratar de forma qualitativa os riscos presentes no ambiente de trabalho. Isto foi possível através do uso do método DeParis para identificação e análise de riscos, bem como para propor soluções para eliminar ou minimizar estes fatores. Cabe ressaltar que os docentes foram envolvidos de forma participativa neste processo. 
O método DeParis se mostrou eficaz neste processo de identificação, análise e proposição de melhorias para eliminar ou minimizar os riscos existentes, permitindo levantar as situações satisfatórias, a melhorar e insatisfatórias.

Dentre as condições satisfatórias, destacam-se: pisos nivelados, não escorregadios e limpos; cadeiras novas e que possibilitam a regulagem das alturas do assento, apoio para as costas e braços; computadores e impressoras novos; autonomia dos docentes na gestão das suas atividades; ambientes limpos e organizados para convívio social; existência de bom relacionamento entre os docentes e os gestores (pró-reitor e diretor).

Já entre as que precisam ser melhoradas, destacam-se: janelas tampadas com papéis; algumas partes das paredes sem pintura; ferramenta de trabalho como a impressora que não apresenta bom funcionamento devido a problemas de conexão e tinta; ruído provocado por conversas entre os docentes e entre docentes e alunos; e, ambiente quente em dias de temperaturas elevadas, devido à ausência de um aparelho de ar condicionado.

As condições insatisfatórias são: mesas de trabalho pequenas; obstrução de acesso aos postos de trabalho por cadeiras; riscos de acidentes com choque devido ao contato com tomadas, quedas de pessoas e materiais, bem como de incêndio pela ausência de uma porta saída de emergência e extintor armazenado inadequadamente.

Um conjunto de ações com responsáveis e prazos foi proposto com o intuito de sanar ou minimizar os impactos das condições a serem melhoradas e insatisfatórias. Além disso, foi proposta uma mudança no layout atual visando proporcionar um ambiente de trabalho com um bom aspecto visual, evitar fluxo cruzado de pessoas e entre pessoas e mobiliário, maior espaço para os docentes executarem suas atividades.

Por fim, sugere-se que o DeParis seja aplicado no espaço que será destinado para alocação dos outros 12 postos de trabalho, bem como após ocorrer a instalação do campus no espaço definitivo para que as rubricas sejam avaliadas perante uma experimentação já consolidada das melhorias propostas atualmente. Deste modo, o método passará a ser uma forma de melhoria contínua na análise das condições de trabalho dos docentes e também se estender na análise de outros postos de trabalho da instituição. 


\title{
Participative Risk Screening (DeParis) applied to the working environment of teaching staff in a federal higher education institution
}

\begin{abstract}
The working environment of professors in public higher education institutions involves several risk factors that can cause harm to the health and physical integrity of these professionals. These factors are mostly caused by the execution of activities under inadequate physical facilities, either by working in temporary spaces, or even by the absence of periodic maintenance in buildings and equipment. The aim of this study is to make use of the DeParis method to identify, analyze and propose actions that eliminate or minimize risks in the working environment of the teaching staff in a federal higher education institution. Therefore, some professionals participated in the process by evaluating their working environment and the related risks. The obtained results showed that the methodology approached was effective in identifying and analyzing the satisfactory conditions, those that needs improvement, and the unsatisfactory conditions, as well as it was effective in proposing actions with achievable deadlines in order to provide a better working environment for the teaching staff to perform their activities.
\end{abstract}

KEYWORDS: DeParis. Working environment. Risk identification. 


\section{REFERÊNCIAS}

MINISTÉRIO DA EDUCAÇÃO (MEC). Análise sobre a Expansão das Universidades Federais 2003 a 2012. Brasília, DF, 2012. Disponível em: < http://portal.mec.gov.br/index.php?option=com_docman\&view=download\&alias =12386-analise-expansao-universidade-federais-2003-2012-pdf\&ltemid=30192>. Acesso em: 21 out. 2017.

BISSACOT, T. C. C.; OLIVEIRA, S. M. A. C. Instrumento para o gerenciamento de riscos ambientais. Engenharia Sanitária e Ambiental, v.21, n.2, p.227-232, 2016. crossref

BREVIGLIERO, E.; POSSEBON, J.; SPINELLI, R. Higiene ocupacional: agentes biológicos, químicos e físicos. 5. ed. São Paulo: Editora SENAC, 2010.

GIL, A. C. Como elaborar projetos de pesquisa. 4. ed. São Paulo: Atlas, 2008.

LIMA, M. F. E. M.; LIMA-FILHO, D. O. Condições de trabalho e saúde do/a professor/a universitário/a. Ciências \& Cognição, v.14, n.3, p.62-82, 2009.

MALCHAIRE, J. (2003). Estratégia Sobane de Gestão de Riscos Profissionais. Disponível em:

$<$ http://www.deparisnet.be/sobane/pt/Estrategia_SOBANE_Port_8-4-09.pdf>. Acesso em: 01 out. 2017.

MALCHAIRE, J. The SOBANE risk management strategy and the Déparis method for the participatory screening of the risks. International archives of occupational and environmental health, v.77, n.6, p.43-50, 2004. crossref

MAZZILLI, S. Ensino, pesquisa e extensão: reconfiguração da universidade brasileira em tempos de redemocratização do Estado. Revista Brasileira de Política e Administração da Educação. São Paulo, v.27, n.2, p.205-221, 2011.

PORTO, M. D.; ALMEIDA, T. C.; TEIXEIRA, Z. D. Condições de trabalho e saúde dos professores das escolas públicas da zona sul da cidade de Manaus. In: Convibra, Disponível em:

<http://www.convibra.com.br/upload/paper/2013/80/2013_80_6404.pdf>. Acesso em: 13 out. 2017.

PRODANOV, C. C.; FREITAS, E. C. Metodologia do trabalho científico. 2.ed. Novo Hamburgo, RS: Feevale, 2013. 
RAMOS, P.; RAMOS, M. M.; BUSNELLO, S. J. Manual prático de metodologia da pesquisa: artigo, resenha, projeto, TCC, monografia, dissertação e tese.

Acadêmica: Blumenau, 2005.

SALIBA, T. M. Manual Prático de Higiene Ocupacional e PPRA. 3.ed. São Paulo: Editora LTR, 2011.

SALIBA, T. M. Curso Básico de Segurança e Higiene Ocupacional. 3.ed. São Paulo: Editora LTR, 2010.

SÁNCHEZ, L. H. Avaliação de impacto ambiental: Conceitos e métodos. 2 ed. São Paulo: Oficina de Textos, 2013.

TOURIÑÁM, J. M. Universidade, Sociedade e empresa: Orientacións estratéxicas de extensión universitária e comunicación institucional. Revista Galega do Ensino, v.44, p.83-110, 2004.

DA SILVA, R.; AMARAL, F. Diagnóstico Participativo de Riscos (DeParis) aplicado ao ambiente de trabalho dos docentes de uma instituição federal de ensino superior. R. Gest. Industr., Ponta Grossa, v. 14, n.4, p. 103-123, out./dez. 2018.em: <https://periodicos.utfpr.edu.br/rgi>. Acesso em: XXX.

Correspondência:

Rodolfo Benedito da Silva

Av. Osvaldo Aranha DEPROT/PPGEP - $5^{\circ}$ Andar, número 99, Bairro Bom Fim, Porto Alegre, Rio Grande do Sul, Brasil.

Direito autoral: Este artigo está licenciado sob os termos da Licença Creative Commons-Atribuição 4.0 Internacional.

\section{(c) (1)}

